\title{
Chronic kidney disease, 24-h blood pressure burden and their effects on silent cerebral injury and cognitive impairment: might age serve as a modulator?
}

\author{
Michiaki Nagai and Kazuomi Kario \\ Hypertension Research (2011) 34, 1253-1254; doi:10.1038/hr.2011.146; published online 1 September 2011
}

$\mathrm{V}$ ascular diseases of the brain are a major cause of death and disability. ${ }^{1}$ Magnetic resonance imaging has revealed that white matter lesions (WML) are common in the elderly ${ }^{2}$ and are associated with stroke. ${ }^{3}$

Given the enigmatic nature of WML, it is important to find novel risk factors that clarify their pathophysiology and serve as targets for risk reduction. Hypertension is a major risk factor for WML, ${ }^{4}$ and ambulatory blood pressure is more closely correlated with WML than is casual blood pressure. ${ }^{5}$

Chronic kidney disease (CKD) has emerged as another independent risk factor for stroke. ${ }^{6} \mathrm{WML}$ is prevalent in patients with end-stage renal disease. ${ }^{7}$ In the Northern Manhattan Study, moderate to severe CKD was associated with increased WML volume, indicating the importance of CKD as a possible marker of cerebral microangiopathy. ${ }^{8}$

In this month's issue, Yamamoto et al. ${ }^{9}$ report their investigation of the relationships among kidney function, ambulatory blood pressure measures, silent cerebral injury and cognitive function in 224 patients with symptomatic lacunar infarction. Non-dipper, riser, estimated glomerular filtration rate (eGFR) $<60$ and moderate to severe WML are independently and significantly associated with cognitive impairment. Advanced age and eGFR $<60$ are significantly associated with severe WML. Therefore, CKD seems to have a causal link with cognitive impairment via WML. Although we recognized that CKD

Dr M Nagai and Dr K Kario are at the Division of Cardiovascular Medicine, Department of Medicine, Jichi Medical University School of Medicine, Yakushiji 3311-1, Shimotsuke, Tochigi 329-0498, Japan. Dr M Nagai is at the Shimoryoke, Soryo, Shobara, Hiroshima, Japan.

E-mail: kkario@jichi.ac.jp has significant relationships with WML and cognitive impairment in this study population, we wondered whether these relationships would hold true in other populations.

Several points should be considered when interpreting the results of Yamamoto et al. ${ }^{9}$ study. First, in the Modification of Diet in Renal Disease (MDRD) equation, age, gender and serum creatinine levels were included in the formula. ${ }^{10}$ Because creatinine was lowered due to muscle loss, the elderly lean subjects tended to have decreased eGFR. With the current staging system, people who are older than 70 years dominate the category of moderate renal impairment (GFR from $30-59 \mathrm{ml} \mathrm{min}^{-1}$ per $1.73 \mathrm{~m}^{2}$ : stage 3$) .{ }^{11}$ Age might therefore serve as a potential modifying factor, specifically for the relationship among $\mathrm{CKD}, \mathrm{WML}$ and cognitive impairment in this study.

Second, the mean eGFR in the population ranged from $49.5-64.5 \mathrm{ml} / \mathrm{min}$ per $1.73 \mathrm{~m}^{2}$. This result should be cautiously interpreted, because the significant association between $\mathrm{CKD}$ and cognitive impairment was shown only in the elderly subjects with relatively decreased eGFR. What is the relationship in the general population? The current MDRD equation was inaccurate for mildly decreased eGFR $\left(60-90 \mathrm{ml} \mathrm{min}^{-1}\right.$ per $1.73 \mathrm{~m}^{2}$ ranges: stage 2), which is called the 'creatinine-blind' range. Although mildly decreased GFR may be considered a 'preclinical' disease, there is little evidence that they are associated with poorer clinical outcomes. ${ }^{12}$

Recently, several low molecular weight endogenous proteins have been evaluated as alternative markers to creatinine. Cystatin $\mathrm{C}$ (CysC), which is rarely affected by muscle loss, has received the most attention. ${ }^{6}$ In the
HiroShima-Shobara-Soryo COhort (3SCO) study, we investigated the relationship between kidney function and cognitive function among the 201 high-risk elderly at cardiovascular disease $(79.9 \pm 6.4$ years old; female, 75\%; anti-hypertensive medication use, $71 \%$ ). Kidney function was estimated on the basis of serum creatinine (eGFRcreat), using the MDRD equation, ${ }^{10}$ and eGFR was estimated on the basis of CysC (eGFRcys), using Hoek's equation: eGFRcys $=-4.32+$ $80.35 \times 1$ CysC. $^{13}$

The mean eGFRcreat and eGFRcys were 88.9 and $92.4 \mathrm{ml} \mathrm{min}^{-1}$ per $1.73 \mathrm{~m}^{2}$, respectively. In the analysis of variance among groups according to the quartile of the Mini Mental State Examination (MMSE) score, eGFRcreat was not significantly different between the groups $(P=0.26$; Figure 1a). However, eGFRcys was significantly different between the groups $(P<0.05$; Figure $1 \mathrm{~b})$. Subjects in the lowest quartile of MMSE score had significantly lower eGFRcys than those in the highest quartile $(P<0.05$; Figure 1b). However, this relationship was attenuated after adjusting for age $(P=0.18)$.

In the high-risk elderly subjects, eGFRcys was more closely associated with cognitive function than eGFRcreat. Earlier studies have shown that serum CysC may be a sensitive indicator in identifying mild reductions in kidney function than serum creatinine. ${ }^{14}$ Therefore, lowered cognitive function might be observed in elderly patients with mildly decreased GFR. In addition, age might serve as a moderator for this relationship.

Based on the results of this and previous studies, decreased kidney function might be an indicator for the cognitive impairment in subjects with moderate-to-severe CKD and 
a
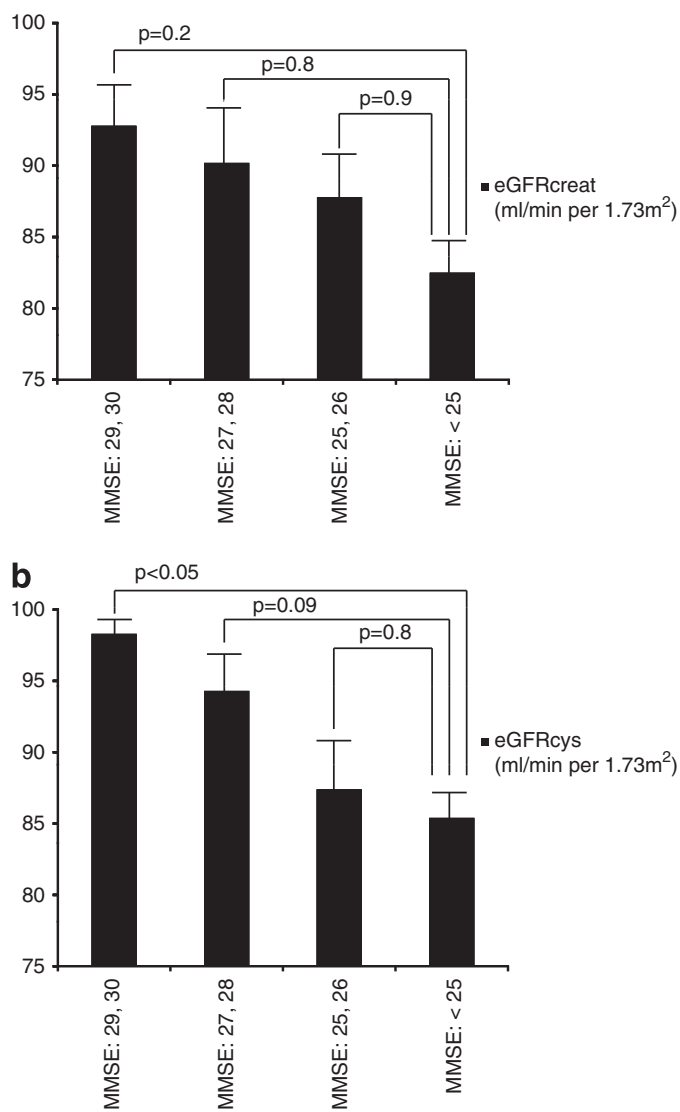

Figure 1 Mean value of estimated glomerular filtration rate (eGFR). Mean eGFR was presented according to the quartile of mini mental state examination (MMSE) score. Analysis of variance was used to determine differences in serum creatinine (eGFRcreat) (a) and CysC (eGFRcys) (b) among four groups. Although eGFRcreat was not significantly different between the groups $(P=0.26)$, eGFRcys was significantly different between groups $(P<0.05)$.

in those with mildly decreased GFR. Until now, there have been few reports assessing the relationship among CKD, WML and cognitive impairment. Therefore, the data presented by Yamamoto et al. ${ }^{9}$ make an important contribution, if they are considered within the context of the study's limitations.

\section{CONFLICT OF INTEREST}

The authors declare no conflict of interest.

1 AHA. Heart Disease and Stroke Statistics - Update 2005.

2 Liao D, Cooper L, Cai J, Toole J, Bryan N, Burke G, Shahar E, Nieto J, Mosley T, Heiss G. The prevalence and severity of white matter lesions, their relationship with age, ethnicity, gender, and cardiovascular disease risk factors: the ARIC Study. Neuroepidemiology 1997; 16: 149-162.

3 Vermeer SE, Hollander M, van Dijk EJ, Hofman A, Koudstaal PJ, Breteler MM. Silent brain infarcts and white matter lesions increase stroke risk in the general population: the Rotterdam Scan Study. Stroke 2003; 34: 1126-1129.

4 Longstreth Jr WT, Manolio TA, Arnold A, Burke GL, Bryan $\mathrm{N}$, Jungreis CA, Enright PL, O'Leary D, Fried L. Clinical correlates of white matter findings on cranial magnetic resonance imaging of 3301 elderly people: The Cardiovascular Health Study. Stroke 1996; 27: 1274-1282.

5 Shimada K, Kawamoto A, Matsubayashi K, Ozawa T. Silent cerebrovascular disease in the elderly. Correlation with ambulatory pressure. Hypertension 1990; 16: 692-699.

6 Shlipak MG, Sarnak MJ, Katz R, Fried LF, Seliger SL, Newman AB, Siscovick DS, Stehman-Breen C. Cystatin C and the risk of death and cardiovascular events among elderly persons. N Engl J Med 2005; 352: 2049-2060.

7 Fazekas G, Fazekas F, Schmidt R, Kapeller P, Offenbacher H, Krejs GJ. Brain MRI findings and cognitive impairment in patients undergoing chronic hemodialysis treatment. I Neurol Sci 1995; 134: 83-88.

8 Khatri M, Wright CB, Nickolas TL, Yoshita M, Paik MC, Kranwinkel G, Sacco RL, DeCarli C. Chronic kidney disease is associated with white matter hyperintensity volume: the Northern Manhattan Study (NOMAS). Stroke 2007; 38: 3121-3126.

9 Yamamoto Y, Ohara T, Nagakane Y, Tanaka E, Morii F, Koizumi T, Akiguchi I. Chronic kidney disease, 24-h blood pressure and small vessel diseases are independently associated with cognitive impairment in lacunar infarct patients. Hypertens Res 2011; 34: 1276-1282.

10 Imai E, Horio M, Nitta K, Yamagata K, Iseki K, Tsukamoto $\mathrm{Y}$, Ito S, Makino H, Hishida A, Matsuo S. Modification of the Modification of Diet in Renal Disease (MDRD) study equation for Japan. Am J Kidney Dis 2007; 50: 927-937.

11 Coresh J, Selvin E, Stevens LA, Manzi J, Kusek JW, Eggers P, Van Lente F, Levey AS. Prevalence of chronic kidney disease in the United States. JAMA 2007; 298: 2038-2047.

12 Levey AS, Eckardt KU, Tsukamoto Y, Levin A, Rossert J, De Zeeuw D, Hostetter TH, Lameire N, Eknoyan G. Definition and classification of chronic kidney disease: a position statement from Kidney Disease: Improving Global Outcomes (KDIGO). Kidney Int 2005; 67: 2089-2100.

13 Hoek FJ, Kemperman FA, Krediet RT. A comparison between cystatin $C$, plasma creatinine and the Cockcroft and Gault formula for the estimation of glomerular filtration rate. Nephrol Dial Transplant 2003; 18: 2024-2031.

14 Rule AD, Bergstralh EJ, Slezak JM, Bergert J, Larson TS. Glomerular filtration rate estimated by cystatin $C$ among different clinical presentations. Kidney Int 2006; 69: 399-405. 